\title{
On associations between the 11-year solar cycle and the Indian Summer Monsoon system
}

\author{
Chantal Claud, ${ }^{1}$ Bertrand Duchiron, ${ }^{1}$ and Pascal Terray ${ }^{2}$ \\ Received 22 May 2007; revised 29 November 2007; accepted 24 January 2008; published 6 May 2008.
}

[1] In this observational study, the associations between the characteristics of the Indian Summer Monsoon (ISM) and the 11-year solar cycle have been investigated using a statistical analysis. A rather complex picture, with considerable spatial variation, has been observed. The most striking features appear in August and to some extent in July, where for higher solar activity, precipitation is reduced over the equatorial Indian Ocean and increased over the western Pacific Ocean and to a lesser extent over part of the Indian subcontinent. In terms of mechanisms, it is suggested that these associations result from a combination of effects: on one side, an effect which maximizes in July-August with warmer temperatures in the lower stratosphere for maximum solar activity, and is consistent with a reduction of the convective activity in the equatorial region and an enhancement in off-equatorial regions; on the other side, a modulation of the mean sea level pressure fields, with a more southerly position of the monsoon trough in June, and a northwestward shift of the Mascarene High in July-August consistent with a stronger monsoon circulation. High solar activity could also cool the February-March SST in the southern Indian Ocean, which weakens the subsequent monsoon. Observations over the period 1871-2001 confirm these associations. As a result of the reported mechanisms, the 11-year solar cycle has poor skill for foreshadowing the ISM as a whole. However, the associations, occurring on the timescale of months, provide a new insight and would be of considerable interest for further modeling studies.

Citation: Claud, C., B. Duchiron, and P. Terray (2008), On associations between the 11-year solar cycle and the Indian Summer Monsoon system, J. Geophys. Res., 113, D09105, doi:10.1029/2007JD008996.

\section{Introduction}

[2] There is still much controversy concerning the effect of the solar cycle on the troposphere, mainly since the percentage change of the total solar radiation between the minimum and the maximum of the solar cycle is very small, and the evidence localized, isolated and sometimes contradictory. The change in the UV (ultraviolet) range of the radiation, and thus ozone heating, is however, one order of magnitude greater and significant [Lean, 1989]. One possible mechanism for explaining the transfer of the solar signal to the surface involves solar ultraviolet irradiance variations affecting ozone, which then changes the temperature and wind patterns in the stratosphere, modulating the vertical propagation of planetary waves from the troposphere. This in turn affects dynamical processes in the troposphere although the precise mechanism for this feedback process is not fully understood [Baldwin and Dunkerton, 2005]. This conceptual model of a downward propagation of direct solar UV-induced effects, from the upper stratosphere to the lower stratosphere, was first proposed by Hines [1974], and then reactivated by various authors [e.g., Haigh, 1994;

\footnotetext{
${ }^{1}$ LMD/IPSL/CNRS, Ecole Polytechnique, Palaiseau, France.

${ }^{2}$ LOCEAN/IPSL/CNRS, Paris, France.
}

Copyright 2008 by the American Geophysical Union. 0148-0227/08/2007JD008996
Hood et al., 1993]. These mechanisms were first simulated using unrealistic solar forcing [e.g., Kodera, 1991] and subsequently with a new generation of General Climate Models, some including interactive ozone chemistry [Haigh, 1996; Shindell et al., 1999]. However, other ideas to relate solar cycle and climate are also developed such as air-sea-radiative coupling at the surface, whereby the spatial asymmetries of solar forcing induced by cloud distributions, would result in different circulation and precipitation regimes [e.g., Meehl et al., 2003, 2008].

[3] Concerning more specifically tropical regions, a number of studies have been carried out during the last two decades in order to assess the impact of the solar cycle on the troposphere. In an observational study, Labitzke and van Loon [1997], have shown that lower stratospheric geopotential ridges correlate with the solar cycle such that ridges tend to be more pronounced in the subtropics under solar maximum conditions. Balachandran et al. [1999], have found, using observations and models, that the geopotential height differences in the troposphere between solar maximum and minimum are statistically highly significant in certain regions, especially in the tropics and subtropics, and that the composite annual averages show a stronger pattern of such solar connection than seasonal averages. Gleisner and Thejll [2003], using NCEP-NCAR data [Kalnay et al., 1996], showed that, when ENSO and volcanic signals are removed, solar signals emerge in the tropics with 
a modulation of the large-scale tropospheric circulation systems. In order to more firmly establish the reality and nature of the detected solar-climate variations and to identify the atmospheric processes involved, identical analyses using ERA-40 reanalysis data sets [Simmons and Gibson, 2000] were conducted: substantially weaker relations were found that were attributed to temporal inhomogeneities in this latter reanalysis [Gleisner et al., 2005]. van Loon et al. [2004], using NCEP/NCAR reanalysis over the period 1979-2002, observed that tropical precipitation regimes during July-August are intensified with increased solar forcing. Their results suggest that the response of the climate system to solar forcing likely results from a combination of dynamically radiative air-sea coupling, in which on one side, increased solar forcing produces higher tropical SSTs, intensifies precipitation regimes, and on the other side, interactions in the upper stratosphere between ozone and UV produce indirect warming of the tropical upper troposphere and lower stratosphere. Haigh et al. [2005], with a simplified global circulation model, showed that perturbations to the heat balance of the stratosphere, such as the one brought by solar activity, can produce changes in the mean tropospheric circulation, even without any direct forcing below the tropopause. More specifically, heating at low latitudes results in a poleward shift of the sub-tropical jets and an expansion of the Hadley cells. These results corroborate studies based on a multiple regression analysis of the NCEP/NCAR [Haigh, 2003] and ERA-40 data sets [Crooks and Gray, 2005], which indicate that the latitudinal extent of the Hadley circulation is increased during solar maximum relative to solar minimum, when considering the annual mean. However, looking at the seasonally averaged response for June-July-August, Crooks and Gray [2005] found a rather ambiguous response in the northern hemisphere that, in their opinion, could be attributed to relative weakness of the climatological background flow in this season. Lately, Salby and Callaghan [2006], also presented evidence in NCEP-NCAR data of a coherent and in phase 11-year solar cycle in the tropical troposphere, but for northern winter (December-January-February). Likewise, van Loon et al. [2007], using observations since the middle of the 19th century, showed a coupled air-sea response to solar forcing in the Pacific region during northern winter.

[4] These latter studies all agree on the fact that the solar cycle response is more easily detected during northern wintertime, which corresponds to the period during which the Brewer-Dobson circulation couples the troposphere to the stratosphere [e.g., Salby and Callaghan, 2006]. An important component of the tropical climate is however the summer monsoon since this major feature of the general circulation dominates the eastern Hemisphere for over onethird of the year. Specifically, for the Indian Summer Monsoon (ISM), there has been in the past studies of possible connections between the ISM rainfall and solar activity. Jagannathan and Bhalme [1973], in a study based on rainfall distribution of a network of 105 stations for more than 50 years, have shown monsoon rainfall distribution patterns to vary as a function of the sunspot cycle. They however noted that the solar influence exhibited considerable spatial variations and was therefore related to changes introduced in the circulation features. They also found a relationship between the solar cycle, the frequency of breaks and the occurrence of storms and depressions. Conversely, Mehta and Lau [1997] found no consistent relationship at the 11 years timescale between the monsoon rainfall and solar irradiance. More recently, Bhattacharyya and Narasimha [2005], in a study based on 120 years of Indian rainfall, have nevertheless reported a link between the solar activity and monsoon rainfall, with regional variations: the strongest connections between solar activity and rainfall are observed along the west coast and in central India, and the weakest in northwest and northeast India. Kodera [2004], using NCEPNCAR data, found that the solar cycle influences the monsoon activity through the modulation of the upwelling in the equatorial stratosphere which produces a north-south seasaw of convective activity over the Indian Ocean Sector during summer. The connection between the stratospheric and tropospheric circulation has been more fully investigated by Kodera and Shibata [2006]. The latter study reveals a clear relationship between the stratospheric meridional circulation and the Indian Ocean monsoon circulation from June to August in the troposphere through four solar cycles.

[5] These sometimes contradictory results point out the need for a comprehensive analysis of the 11-year solar cycle effects on the whole Indian summer monsoon system (i.e., separately from June until September, taking into account the different forcings), associated to the search for possible mechanisms. The existence of the so-called reanalyses, which consist of long global records of data, enables to reconsider the question of the association between solar cycle and ISM. It must be kept in mind that such an association, if any, could be also relevant for the long-range forecasting of ISM, the variability of which has impacts on practically all facets of societal and economic activities in the region. In this paper, we carry out a statistical analysis of the NCEP R-2 [Kanamitsu et al., 2002] monthly mean data covering the period 1979-2001, thus encompassing about two solar cycles. For comparison, ERA-40 [Simmons and Gibson, 2000] data were also used. Although data exist over a longer period for the previous NCEP-NCAR reanalysis and ERA-40, we choose to use only the period since 1979, because use is made of satellite data for the whole period (possible shifts due to their use or not are therefore avoided). It has been checked that a similar work using the reanalyses over a longer period (since 1957) produced results which are in line with those discussed here. In addition, these data sets were complemented by surface reanalyses that exist over much longer time periods and have been created by blending marine and land observations.

[6] The paper is organized as follows. The data sources and statistical methodology are briefly described in section 2 . In section 3, correlations between the solar cycle and monsoon precipitation are first discussed; then, the tropospheric signatures of the solar cycle associated with ISM atmospheric circulation are presented. In section 4, possible mechanisms by which the 11-year variation of solar irradiance can influence the ISM are discussed. Our conclusions appear in the last section of the paper.

\section{Data and Method}

\subsection{NCEP/NCAR Reanalysis}

[7] Use was made of the NCEP R-2 reanalysis data [Kanamitsu et al., 2002] to characterize the links between 
the 11-year solar cycle and the monsoon. NCEP R-2 is an improved version of the NCEP-NCAR reanalysis [Kalnay et al., 1996] that fixed errors and updated parameterizations of some physical processes. NCEP-NCAR reanalysis covers the period from January 1956 through December 2000, while NCEP R-2 is available from January 1979 through December 2001. The model is run at a horizontal resolution of T62, with 28 vertical levels. Geopotential heights, temperatures and winds in the troposphere are available at 12 levels from 1000 to $100 \mathrm{hPa}$. Data are given on a $2.5 \times$ $2.5^{\circ}$ latitude/longitude grid. Winds at 850 and $200 \mathrm{hPa}$ from NCEP-R2 have been considered to characterize the monsoon surface and upper-level circulation, respectively. The $500 \mathrm{hPa}$ vertical velocity (w) has also been considered to describe the areas of deep convection. For addressing the issue of the mechanisms involved in the solar-monsoon relationships, temperature at various stratospheric levels has also been used.

\subsection{ERA-40 Reanalysis}

[8] For comparison, use was also made of the ERA-40 data assimilation system [Simmons and Gibson, 2000] which uses the Integrated Forecasting System (IFS) developed jointly by ECMWF and Météo-France. A three-dimensional variational method is used to assimilate the observations into the spectral model, which has 60 vertical levels and T159 horizontal spectral resolution. Data are available since 1957 for 23 pressure levels with a spatial resolution of $1.125^{\circ}$. Prior to 1972 , the atmospheric measurements available to ERA-40 are limited mainly to radiosondes. Since then, the reanalysis makes comprehensive use of satellite data; however, since NCEP-R2 data and global precipitation fields (see below) are available only after 1979, ERA-40 results presented here cover the period 1979-2001. A more detailed description of the ERA-40 data set can be obtained online at http://wwww.ecmwf.int/ research/era.

\subsection{Independent Observational Data Sets}

[9] Global precipitation fields called CMAP (Climate Prediction Center Merged Analysis Precipitation) [Xie and Arkin, 1996, 1997] have been considered. CMAP is a gridded global monthly precipitation constructed on a $2.5 \times$ 2.5 degree latitude/longitude grid, and covering the period from 1979 until 2001. It relies on gauge observations and on estimates of precipitation inferred from microwave and infrared satellite observations. For completeness, the Indian Monsoon Rainfall (IMR) index chosen in this study is the All India Rainfall Index, as defined by Parthasarathy et al. [1995], since it has been shown to be the most accurate measure of rainfall over the Indian subcontinent [Annamalai et al., 1999]. It is an area-weighted average of six homogeneous regions (Peninsular, northwest, northeast, central northeast, west Central and a so-called homogeneous Indian monsoon). Seasonal averages as well as monthly values of IMR have been used in this study.

[10] Despite the fact that Sea Surface Temperatures (SST) are available in both NCEP-R2 and ERA-40, we have considered Extended reconstructed SST (ERSST), which correspond to a monthly extended reconstruction of global SST based on Comprehensive Ocean-Atmosphere Data Set and underwent a severe quality control [Smith and Reynolds,
2003, 2004]. SST are available after 1854 on a $2^{\circ}$ spatial grid at: http://lwf.ncdc.noaa.gov/oa/climate/research/sst/sst. html\#ersst.

[11] Mean sea level pressures (mslp) from the Hadley Centre, available since 1850 , have also been used. In this reanalysis, land and marine observations have been blended in a way that local details are restored by the superposition of quality-improved gridded observations on the reconstructions [Allan and Ansell, 2006]. The spatial resolution is $5^{\circ}$ latitude by $5^{\circ}$ longitude.

[12] Previous studies that have tested different proxies for the solar activity [e.g., Donnelly et al., 1986; Keckhut et al., 1995], have shown that the 10.7-cm solar flux closely tracks the temporal behavior of the UV changes on 11-year timescales [Keckhut et al., 2005]. Therefore for the analysis of the recent period, the $10.7-\mathrm{cm}$ radio flux (F10.7) has been considered. Since this index is not available before 1956, the sunspot number, which spans the longest time period, has been considered for the analysis of mslp and ERSST. It is available at: http://sidc.oma.be/. The temporal evolution of F10.7 and the sunspot number, displayed on Figure 1, illustrates the high correlation between the two series, in spite of a slight systematic bias (F10.7 values lower than sunspot values).

\subsection{Statistical Analysis}

[13] To highlight the space-time structure of the monsoon and the solar-monsoon links, standard lead-lag crosscorrelation and regression techniques between F10.7 (or the sunspot number for longer time series) and atmospheric fields have been performed. The statistical significance of the results has been assessed with a phase-scrambling bootstrap test with 999 samples [Davison and Hinkley, 1997], taking into account the autocorrelation characteristics of the time series.

[14] A phenomenon that further complicates the identification of solar influence on climate is the Quasi-Biennial Oscillation (QBO), which dominates the interannual variability of the equatorial stratosphere and even influences higher latitudes significantly [e.g., Baldwin et al., 2001]. It consists of zonally symmetric regimes of easterly and westerly winds, which descend through the middle and lower stratosphere at a rate of about $1 \mathrm{~km}$ per month. Claud and Terray [2007] have shown that zonal winds at $15 \mathrm{hPa}$ during the preceding winter (January-February) show the highest association with the summer rainfall over the Indian subcontinent as a whole. To address if and how the solar activity can affect the monsoon independently from the $\mathrm{QBO}$, at each grid point, a standard regression analysis between the various fields and the QBO signal, as described by the winter $15 \mathrm{hPa}$ zonal winds, is first performed. The resulting residual values, uncorrelated with the QBO index, are then correlated with the F10.7 time series as explained above. Likewise, volcanic effects have also been accounted for by considering the Atmospheric Optical Thickness provided on http://data.giss.nasa.gov/modelforce/strataer extended to 2001 by keeping the 1999 level constant. Finally, previous studies on the ISM-ENSO relationship have shown that a majority of warm episodes in the central and eastern equatorial Pacific are accompanied by below-normal summer rainfall over India. The situation is reversed during cold events. These precipitation changes are associated with 


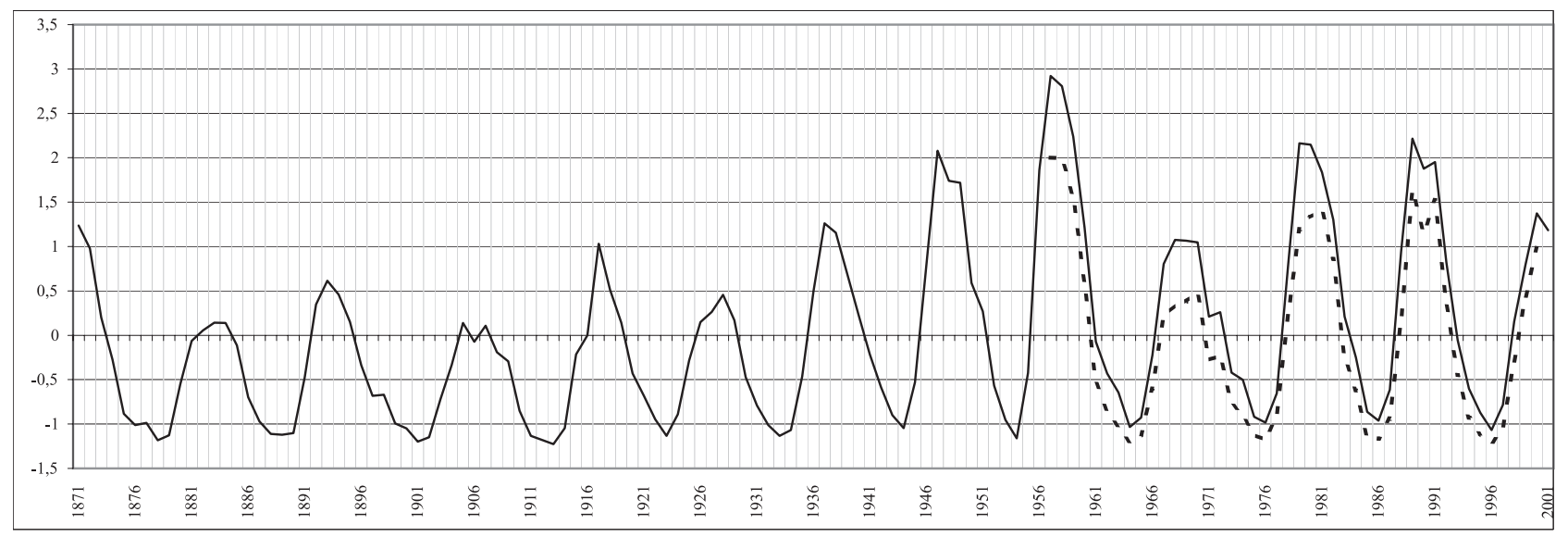

Figure 1. Solar cycle index corresponding to the standardized sunspot number for the period 18712001 (continuous line) and $10.7 \mathrm{~cm}$ solar radio flux for the period 1957-2001 (dashed line).

well-defined circulation features over the monsoon regions: dry conditions have been shown to coincide with lowlevel anticyclonic anomalies over the Arabian Sea and the surrounding land areas, and vice versa [e.g., Lau and Nath, 2000]. For this reason, in the next section, results are shown once the ENSO signal has also been removed from the original time series by the linear regression method.

\section{Results}

\subsection{Correlation Between the Solar Cycle and Monsoon Rainfall}

[15] In a first step, the relationship between the solar cycle, as described by F10.7, and the spatial variability of ISM rainfall has been investigated. According to Kodera and Shibata [2006], the response of the monsoon to the solar cycle could be delayed by one year. Therefore tests have been performed in order to assess if a lag should be considered. The highest, though very little changed, correlations were obtained when an index based on the winter months was chosen. In any case, the advantage of using a 1-year lag could not be demonstrated without ambiguity. Therefore in the following, F10.7 represents the averaged winter value of F10.7, which means that we consider approximately a 6-months lag for summer monsoon.

[16] Figure 2 shows correlations between F10.7 and CMAP rainfall fields during the monsoon season for the 1979-2001 period. In June (Figure 2a), significant positive correlations are observed at the southernmost part of India and between 15 and $25^{\circ} \mathrm{N}$, while the Arabian Sea is characterized by significant negative correlations, especially significant in the western part. Conversely, east of $100^{\circ} \mathrm{E}$, positive correlations are observed over the western Pacific Ocean. In July (Figure 2b), the southern part of India again shows positive correlations, together with the Arabian Sea. The northern part of India exhibits mostly negative correlations. It is in August (Figure 2c) that the correlations are the largest and the most significant (reaching 95\%). The equatorial Indian Ocean and the warm pool are characterized by significant negative values, unlike the equatorial western Pacific Ocean (east of $140^{\circ} \mathrm{E}$ ) which exhibits positive values. Over the Indian subcontinent, correlations are generally positive, except to the southeast and along the Gangetic valley, but are hardly significant. In September (Figure 2d), the global situation is less contrasted. Over India, correlations are positive south of $20^{\circ} \mathrm{N}$, negative north of it and seldom significant.

[17] Figure 2 illustrates the complexity of the association between the solar cycle and precipitation, from both a temporal and a spatial point of view. This is confirmed by systematic correlation analyses between IMR and F10.7 for the period 1957-2001. When considering the global IMR (both monthly values and seasonal average), the correlations are weak and not significant. When performing calculations subdivision by subdivision, however, significant correlations are found with the Peninsular region in June (positive correlation of $0.3,95 \%$ significant), and the Northeast region in June (negative correlation of -0.29 , 95\% significant) and in August ( $-0.28,90 \%$ significant).

[18] In the following, statistical analyses of monsoon circulation fields are carried out in order to first characterize, and then give some clues to understand the dynamical linkage between the monsoon circulation and the solar cycle.

\subsection{Evolution of Solar Related Monsoon Circulation Anomalies}

[19] In order to identify the atmospheric circulation patterns associated with the 11-year solar cycle during the monsoon season, correlation and regression patterns between winter F10.7 and the NCEP-R2 reanalyzed $850 \mathrm{hPa}$ wind and $500 \mathrm{hPa}$ vertical velocity fields for each month of the summer monsoon have been determined for the period 1979-2001. The $500 \mathrm{hPa}$ vertical velocity (w) anomalies have been superimposed on the $850 \mathrm{hPa}$ wind regression patterns in order to describe vertical motion. Note that areas characterized by negative (positive) $500 \mathrm{hPa}$ vertical velocity anomalies correspond to anomalous ascent (subsidence) and increased (decreased) convection. Moreover, only features that exhibit correlations exceeding the $90 \%$ confidence level are displayed in following figures.

[20] At $850 \mathrm{hPa}$, the prominent monsoon wind systems are first the cross-equatorial flow along the east coast of Africa (see Figure 3 which provides a northern summer 

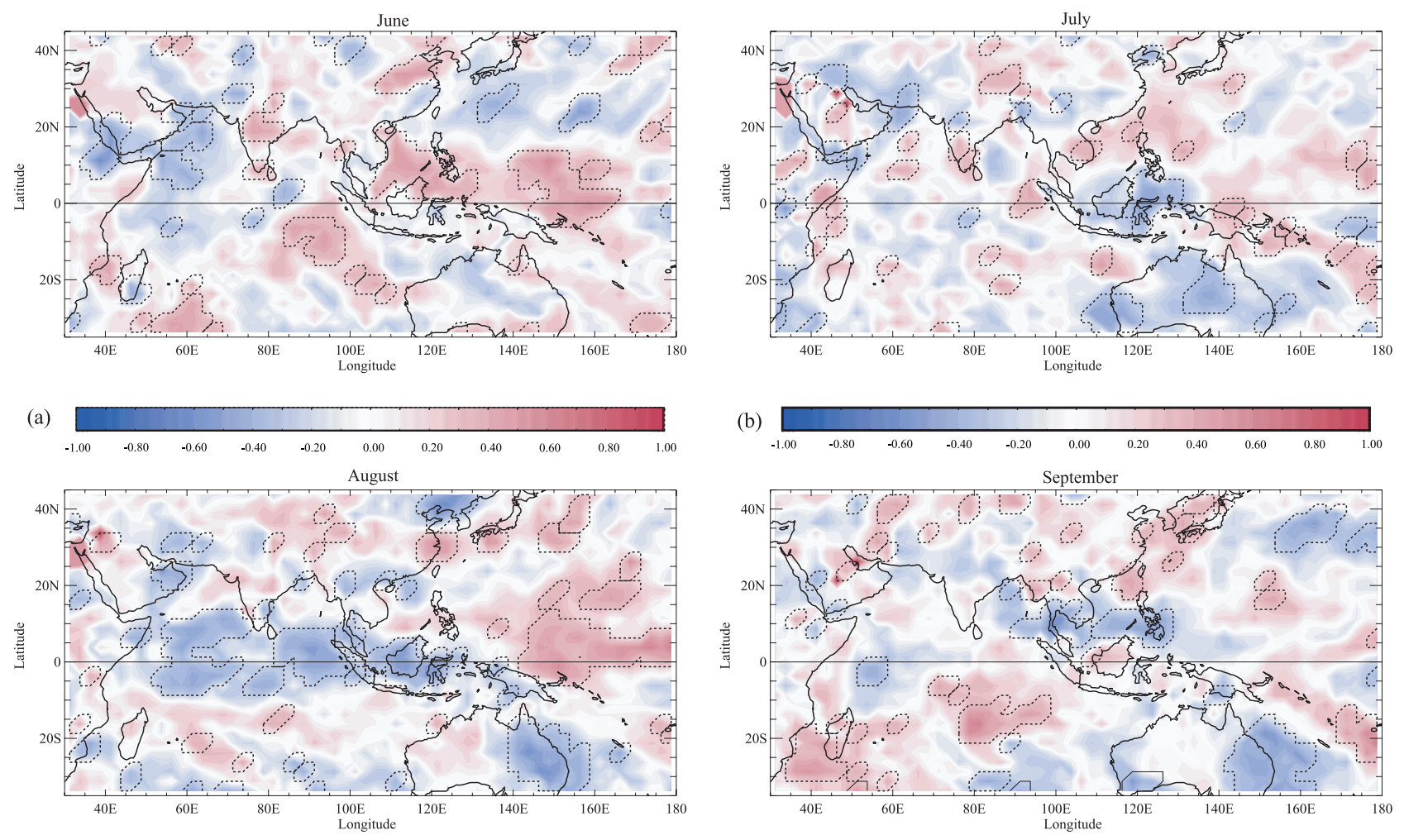

(c)

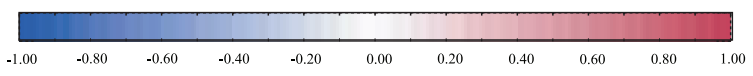

(d)

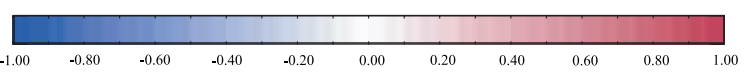

Figure 2. Distribution of correlation coefficients of CMAP precipitation versus F10.7 for (a) June, (b) July, (c) August and (d) September. Correlation coefficients have been computed for the 1979-2001 period. Dotted line contours denote the $90 \%$ confidence level following a phase-scrambling procedure with 999 samples. See text for more details.

climatology of the wind at $850 \mathrm{hPa}$ and $\mathrm{w}$ at $500 \mathrm{hPa}$ ) and second the easterly trade winds in the tropical Pacific. Under the effect of the Coriolis force, the cross equatorial flow becomes the southwest monsoon in South Asia and meets with the trade winds in the western Pacific. Figure 4 displays the distribution of the monthly regression coefficients with F10.7 from June until September. In June (Figure $4 \mathrm{a}$ ), there is an increased cross-equatorial flow in case of maximum solar conditions in an area between 60 and $80^{\circ} \mathrm{E}$ barely significant at the $90 \%$ level, that is, well to the east of the regular position of maximum cross-equatorial flow. This leads to anomalous westerlies over south India (and correlatively, anomalous ascent) and over the Bay of Bengal. This feature is associated with an anticyclonic circulation in the southern Indian Ocean to the west of Australia. In agreement with CMAP maps, easterlies are increased over the warm pool. In July (Figure 4b), the Somali Jet is stronger, with an increased cross-equatorial flow to the west of the Arabian Sea (significant at the 95\% level) and also south of India, where it is associated with increased ascent. It is in August (Figure 4c) that the signature is the most striking: the monsoon circulation is enhanced, with an increase of the cross equatorial flow to the west of the Arabian Sea and to the east of the Bengal Gulf (both patterns significant at the 95\% level). In terms of vertical velocity, in agreement with CMAP results, maximum solar conditions are associated with anomalous sub- sidence over the Equatorial Ocean, while increased ascent can be seen to the north over the Indian Peninsula and southeastern Asia and over the western Pacific. In September (Figure 4d), reduced ascent together with weaker circulation are observed in the Gangetic plains, which reflect a decrease of the rainfall activity. In the south Indian Ocean, the vertical velocity anomalies are in favor of an eastward displacement of the Mascarene High, consistent with a weakening of the monsoon. Correlations calculated over the period 1957-2001 (not shown) are consistent with the results discussed below, even if in July and September, winds are significant over a larger area in the Arabian Sea.

[21] For completeness, similar regressions have been calculated using the ERA-40 reanalysis. They are displayed for June (Figure 4e) and August (Figure 4f). These results have been obtained using full resolution ERA-40 data, but the plots correspond to a $2^{\circ} 5$ sampling for a more direct comparison with NCEP results. They illustrate the rather fair agreement in terms of wind speeds, with some differences in terms of vertical velocity (generally higher correlations when considering ERA-40, but over smaller areas, and differences such as in August over the Bengal Gulf). Over the areas where there is some disagreement, it must be noted than NCEP results (Figures $4 \mathrm{a}-4 \mathrm{~d}$ ) are more in line with CMAP results (Figure 2) than ERA-40 results. These results were partly expected due to the fact that CMAP products includes to a certain extent NCEP reanalysis 


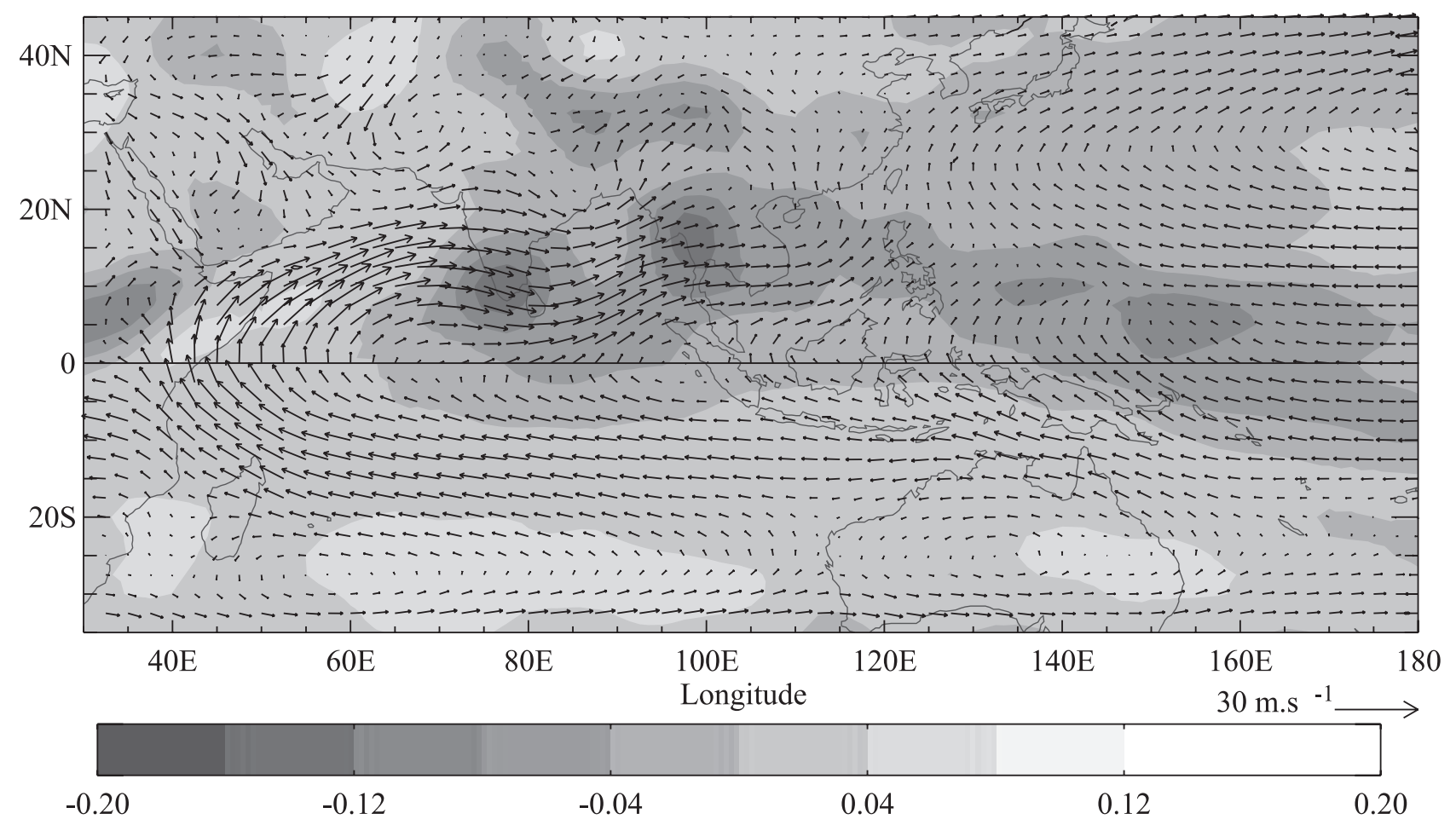

Figure 3. $850 \mathrm{hPa}$ wind (in $\mathrm{m} / \mathrm{s}$ ) and $500 \mathrm{hPa}$ vertical velocity (in $\mathrm{Pa} / \mathrm{s}$ ) northern summer (from June to September) climatology over the period 1979-2001, as derived from the NCEP-R2 reanalysis.

precipitation (for details, see Xie and Arkin [1997]); but they could also partially substantiate results by Crooks and Gray [2005] and Gleisner et al. [2005],who have pointed some weaknesses of the ERA-40 data set.

[22] To assess the effect of the solar cycle on the upperlevel circulation, regressions have also been calculated for the $200 \mathrm{hPa}$ wind and geopotential height (not shown). At this level, the most outstanding features of the summer monsoon are the huge anticyclonic circulation (the so-called Tibetan High) centered over the southern edge of the Tibetan Plateau, and the cross-equatorial flow from the northern to the southern hemisphere along the eastern and southern periphery of the Tibetan High. From July to September, in solar maximum conditions, the Tibetan High is slightly weaker and shifted eastward (not shown). In August, the cross equatorial flow is significantly increased over the warm pool. Similar features appear when considering corresponding fields for the ERA-40 reanalysis (not shown).

\section{Discussion}

[23] The preceding results provide an unprecedented complex picture of the associations between the 11-year solar cycle and the ISM. While a number of published papers insisted on the global intensification of the monsoon with increased solar flux, this study shows that it is prominent only in August and to some extent in July. In addition, over the period 1979-2001, in case of high solar activity, precipitation is increased along the west coast and to the south of about $20^{\circ} \mathrm{N}$ with the exception of the southeast of the Peninsula in August, but some regions, especially to the north, are characterized by less precipitation. This probably explains why some authors did not found consistent relationships between monsoon rainfall and solar irradiance at the 11 years timescale [Mehta and Lau, 1997]. In order to better understand the linkages between the monsoon rainfall characteristics and the solar cycle, further statistical analyses have been carried out, and are described below.

[24] Since one of the mechanisms proposed to explain the linkages between the solar forcing and the climate system involves the stratosphere, correlation and regression patterns between winter F10.7 and the NCEP-R2 reanalyzed stratospheric temperature fields have been determined for the period 1979-2001. As an example, the impact at $50 \mathrm{hPa}$ is displayed in Figure 5, and it has been checked that it is similar at other levels in the low stratosphere. The signature consists of two lobes of warmer temperatures situated about $25-30^{\circ}$ from the equator, that peak in July-August (Figures $5 b-5 c$ ) for larger values of F10.7. Note that these regions are significant at the $99 \%$ significant level. This warming is consistent with a reduction of the convective activity in the equatorial region and an enhancement of convective activity in off-equatorial regions [Kodera, 2004], which is synonymous of a strengthening of the monsoon. However, this north/south seasaw in convective activity alone cannot lead to the complex picture presented above of the associations between F10.7 and the Indian summer monsoon, and in particular, the opposition between the negative correlation values over the equatorial Indian Ocean and the warm pool and the positive correlation values over the equatorial western Pacific Ocean observed in August (Figure 2c). Therefore other explanations have to be found.

[25] Because the variability of the monsoon system is associated to the inter-hemispheric pressure gradient, correlations between the 11-year solar cycle and the mean sea 

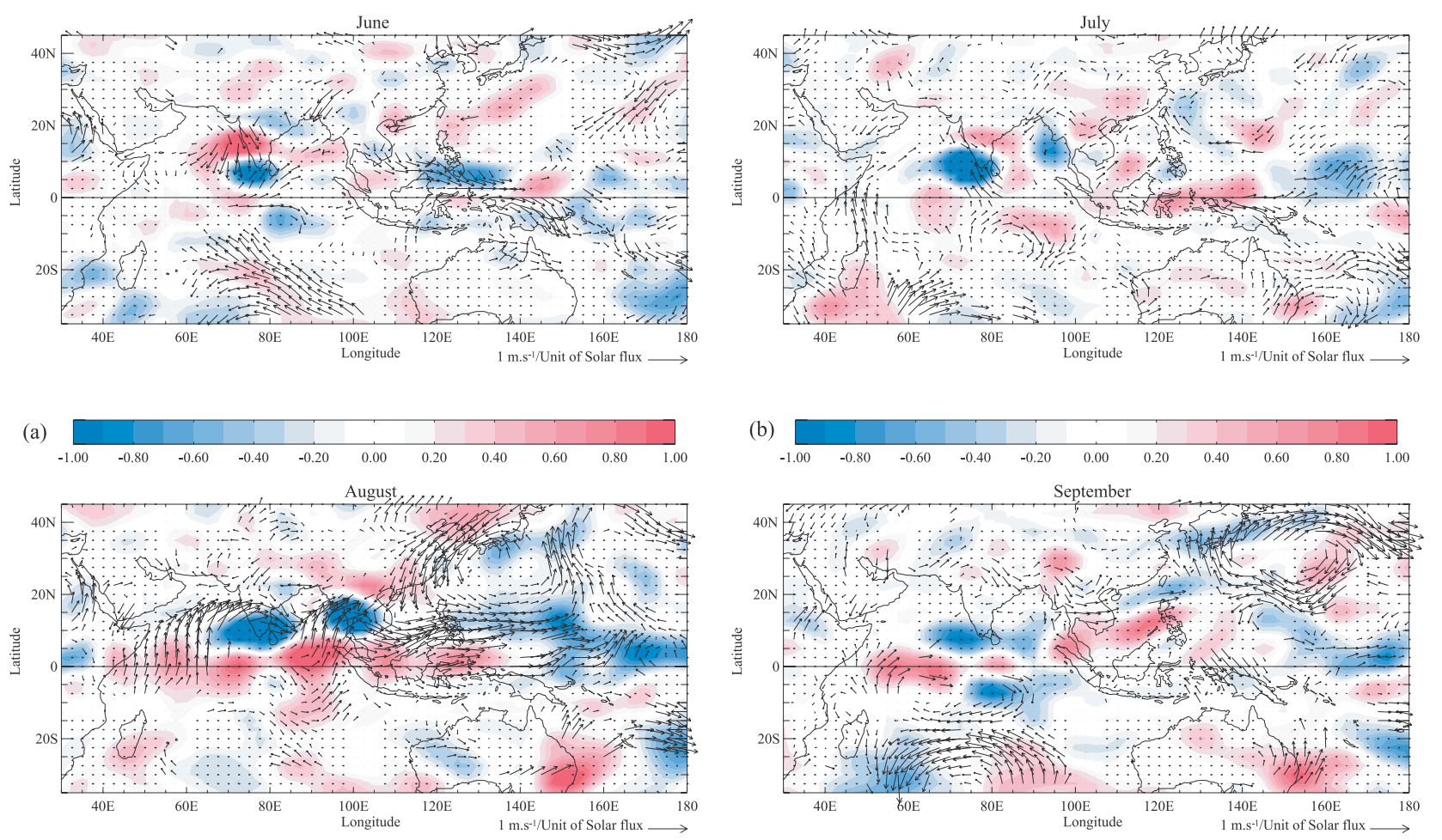

(c)
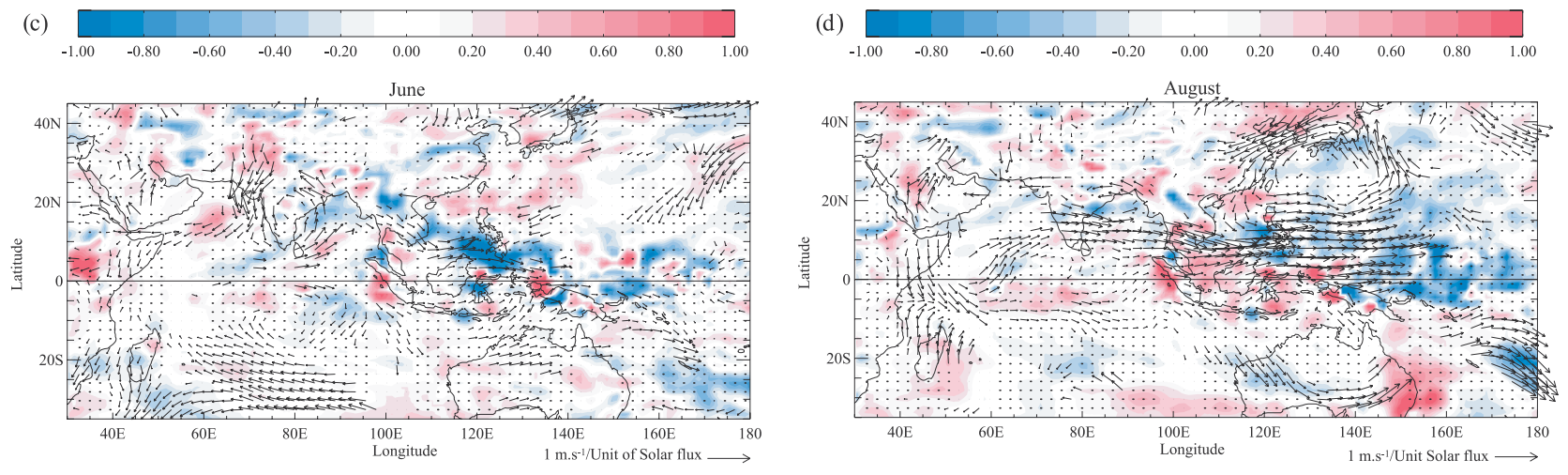

(e)

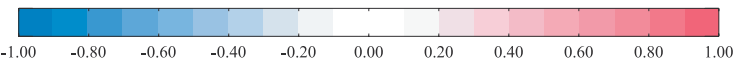

(f)

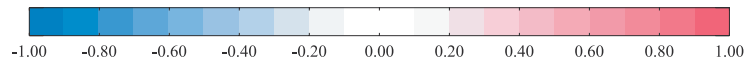

Figure 4. Distribution of monthly regression coefficients of $850 \mathrm{hPa}$ wind and correlation coefficients of $500 \mathrm{hPa}$ vertical velocity versus F10.7 for: (a) June, NCEP-R2 fields (b) July, NCEP-R2 fields (c) August, NCEP-R2 fields (d) September, NCEP-R2 fields (e) June, ERA-40 fields (f) August, ERA-40 fields. Regression and correlation coefficients have been computed for the 1979-2001 period. Maps only show wind vectors and omega values corresponding to coefficients above the $90 \%$ confidence level following a phase-scrambling procedure with 999 samples. See text for more details.

level pressure (mslp), as provided by the Hadley Centre data set, have been determined. To help the interpretation of the results, a mslp climatology is first displayed in Figure 6. During northern summer, there is a strong inter-hemispheric pressure gradient due to the low pressure system established north of $20^{\circ} \mathrm{N}$ and the Mascarene High in the south Indian Ocean. Figures $7 a-7 d$ display the distribution of the monthly correlation coefficients of mslp versus the sunspot number over the period 1957-2001. This longer period was chosen because it covers 4 solar cycles, this analysis is mainly based on local observations, and it has been checked that results are in line with those obtained over the 19792001 period. In June (Figure 7a), a salient feature concerns the large significant positive correlation between the sunspot number and mslp over the Tibetan Plateau and Central Asia. The northwestward shift of the Mascarene High (with significant positive correlations to the west of the subtropical Indian Ocean) could explain the lack of precipitation over the northwest Arabian Sea. Conversely, over the Indian subcontinent, there is a southwest-northeast anomaly gradient in the mslp correlation fields (though correlations are not significant at the $90 \%$ level over Peninsular India). This 

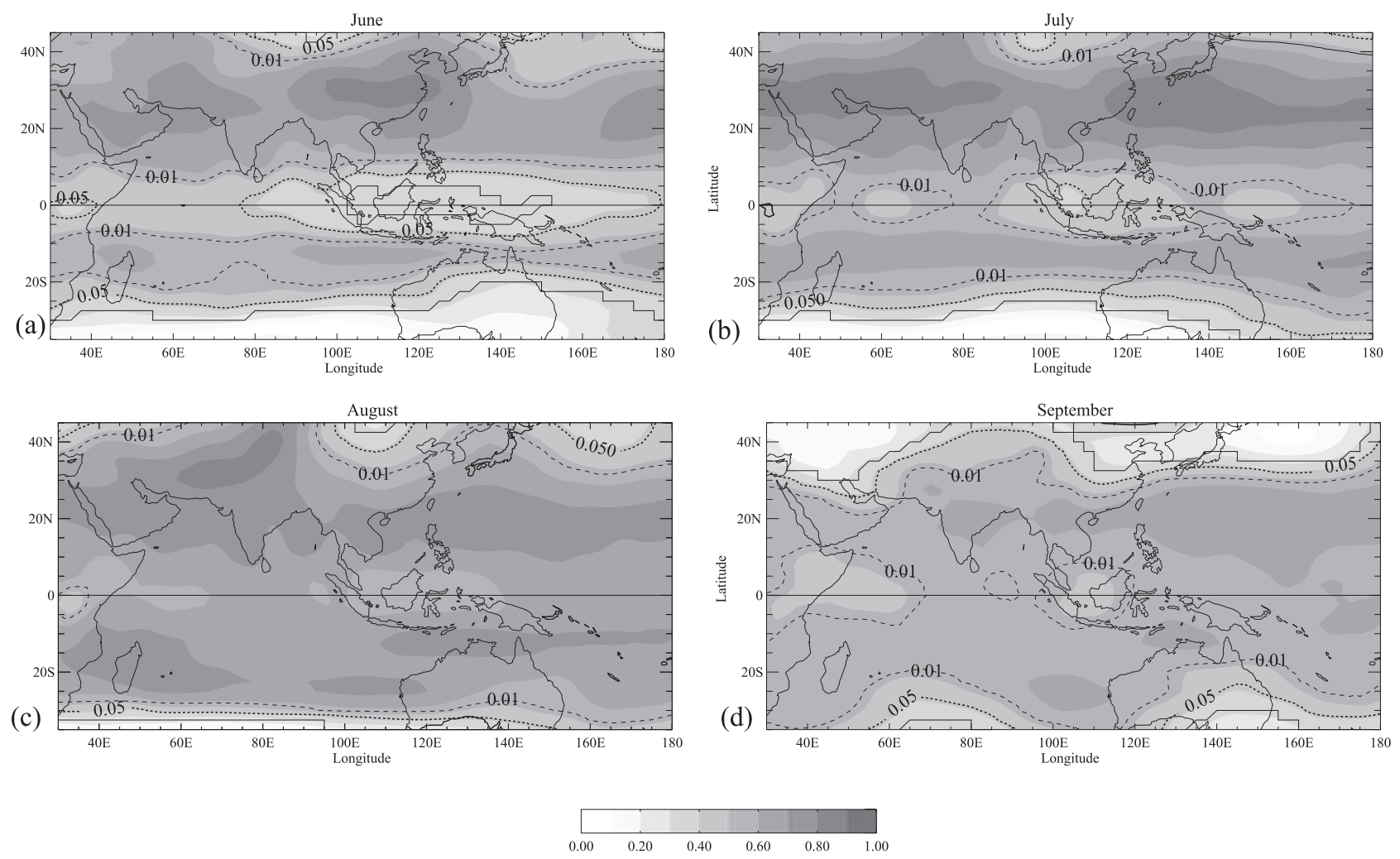

Figure 5. Distribution of correlation coefficients of $50 \mathrm{hPa}$ temperature versus F10.7 for (a) June, (b) July, (c) August and (d) September. Correlation coefficients have been computed for the 1979-2001 period. The confidence level following a phase-scrambling procedure with 999 samples has been superimposed (dashed line: 90\%, dotted line: $95 \%$ and continuous line: 99\%). See text for more details.

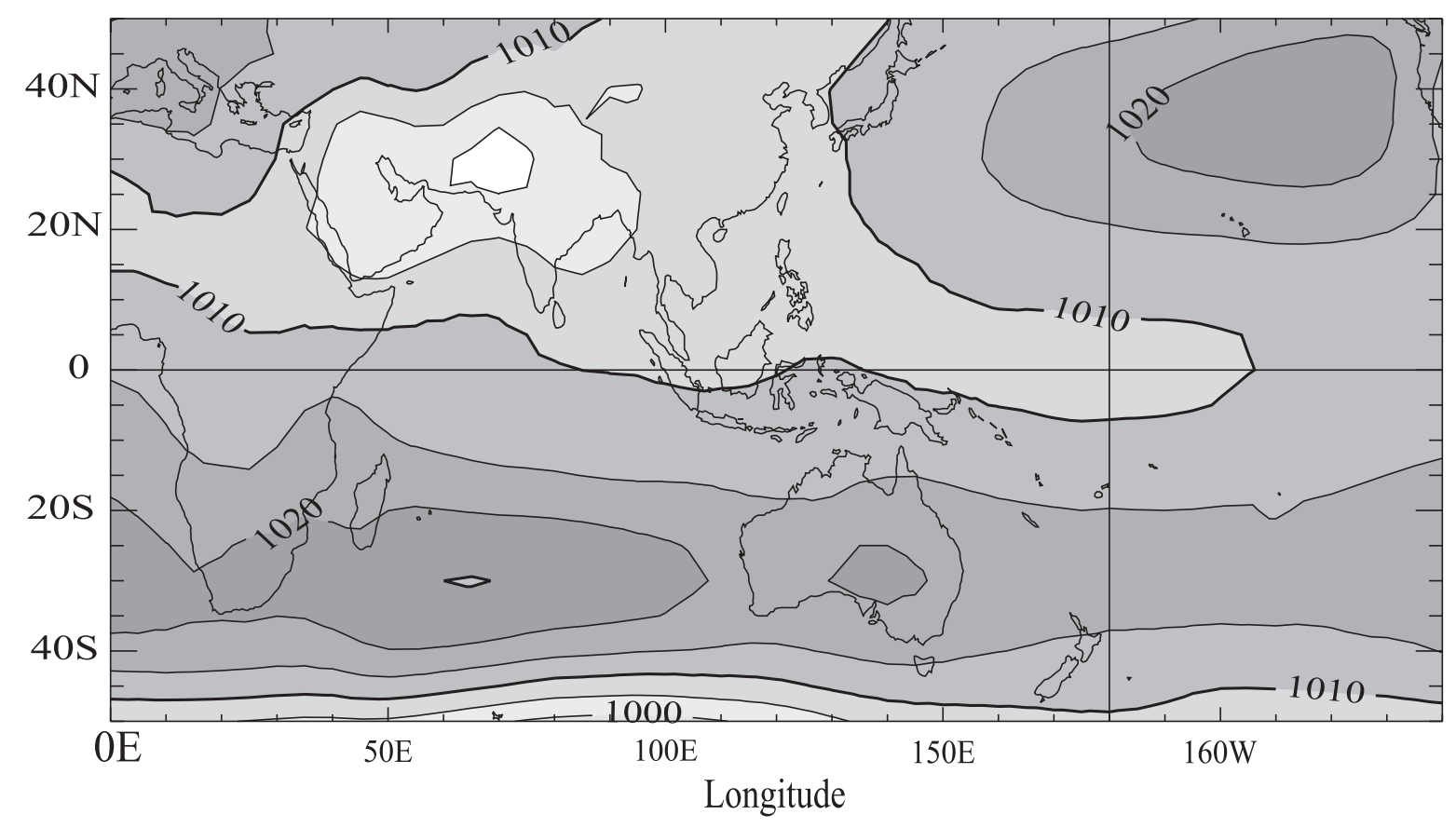

Figure 6. Mean Sea level pressure (in $\mathrm{hPa}$ ) northern summer (from June to September) climatology over the period 1957-2001, as derived from the Hadley Centre data. 

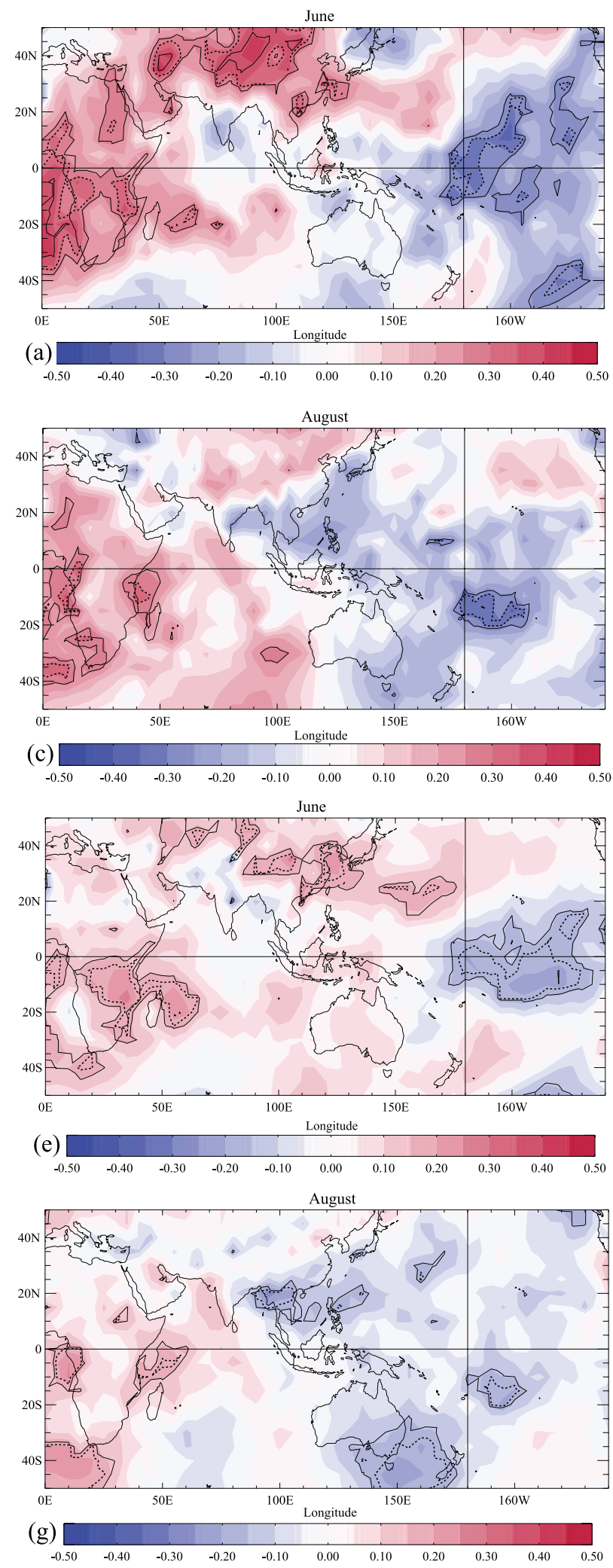
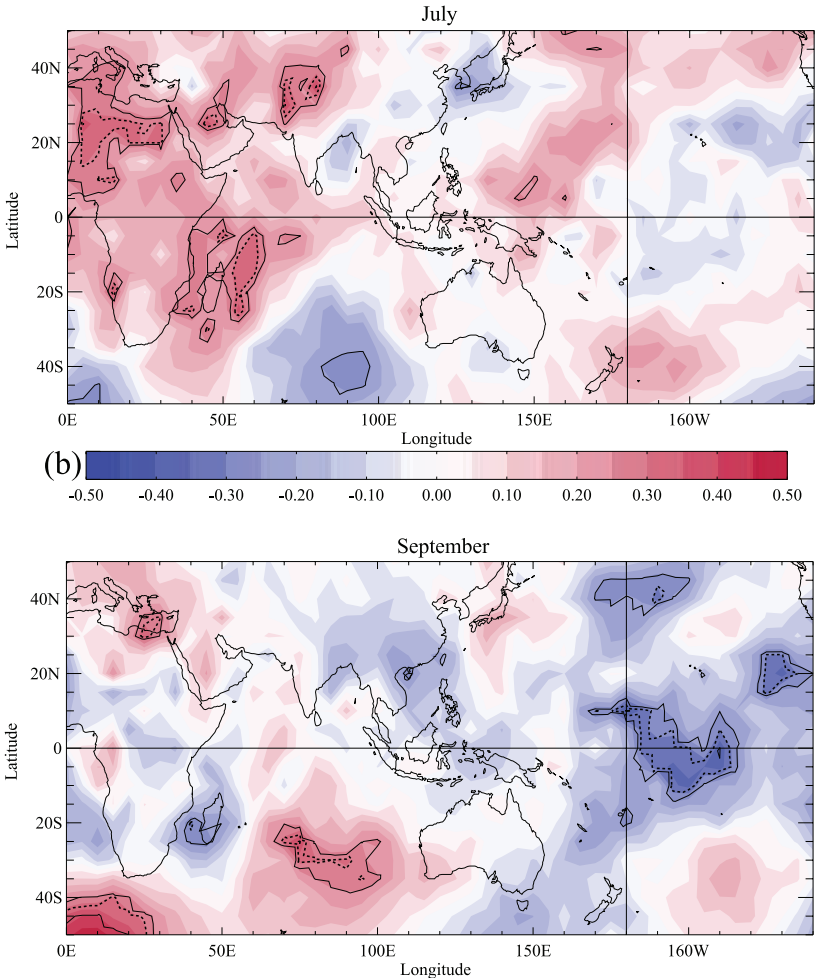

(d)
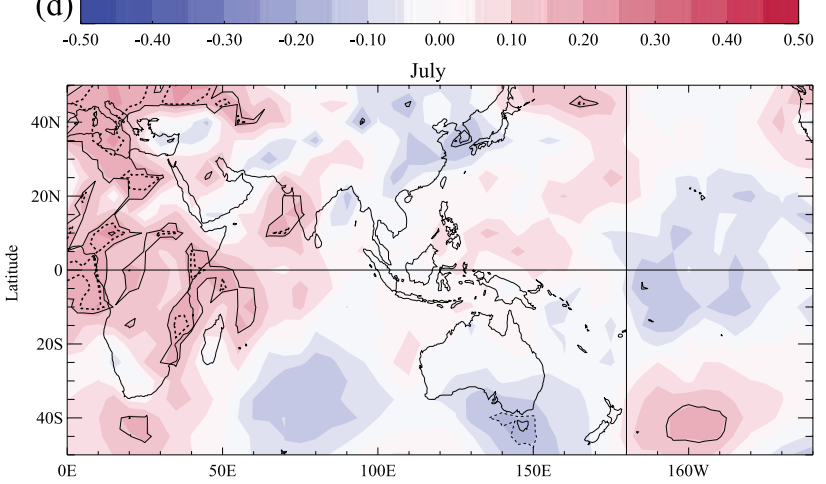

(f)
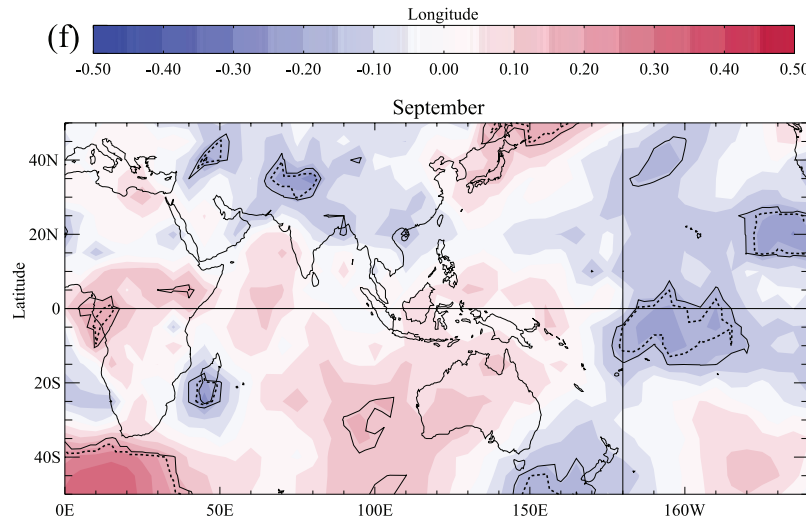

(h)

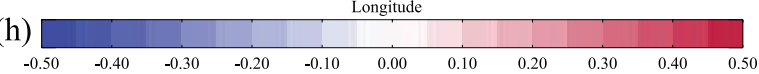

Figure 7. Distribution of monthly correlation coefficients of mslp versus the sunspot value for (a) June, over the period 1957-2001; (b) July, over the period 1957-2001; (c) August, over the period 19572001; (d) September over the period 1957-2001; (e) June, over the period 1871-2001; (f) July, over the period 1871-2001; (g) August, over the period 1871-2001; (h) September over the period 1871-2001. Continuous (dotted) line contours denote the $90 \%$ (95\%) confidence level. Note that the scale is from -0.5 to 0.5 . 

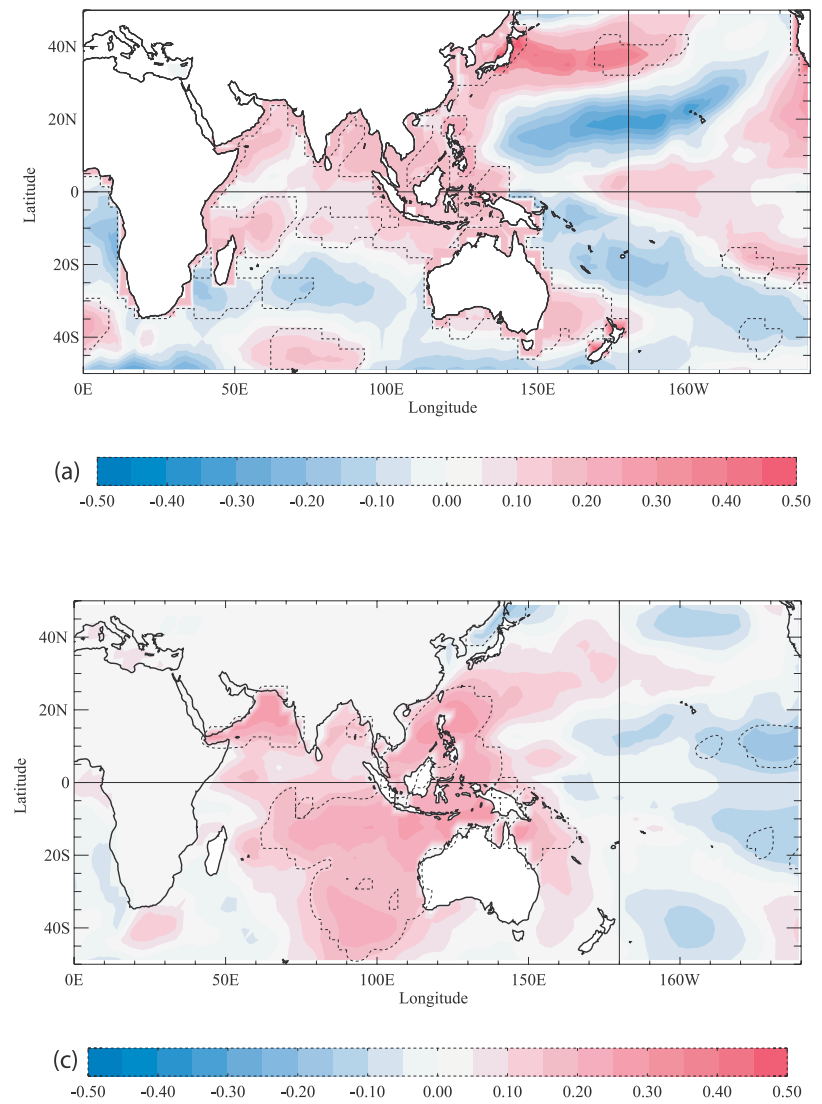

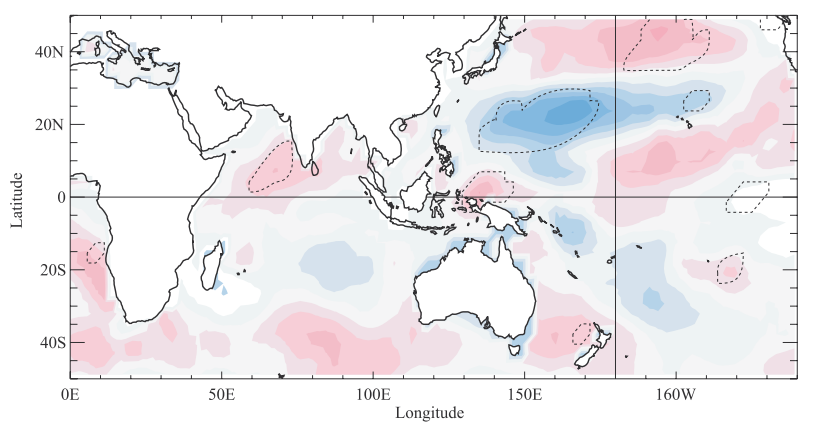

(b)

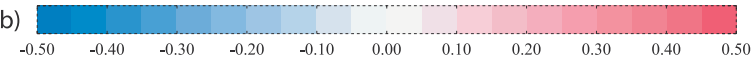

Figure 8. Distribution of monthly correlation coefficients of SST versus the sunspot value for the averaged February-March months (a) for the period 1957-2001, (b) for the period 1871-2001, (c) for the period 1871-2001, but versus the Indian Monsoon Rainfall (IMR) index. Dotted line contours denote the $90 \%$ confidence level following a phase-scrambling procedure with 999 samples. Note that the scale is from -0.5 to 0.5 .

suggests a latitudinal shift of the main axis of the monsoon trough [e.g., Cadet, 1983]. A more southerly (northerly) position of the monsoon trough is associated with positive (negative) rainfall anomalies over Peninsular India and negative (positive) anomalies over the northeastern part of India (Figure 2a) in agreement with results of Terray [1995]. Positive correlations are still present in the western part of the Indian Ocean in July-August (Figures 7b-7c), but not any more in September (Figure 7d). There is a high degree of consistency with the response to the solar activity for a period as long as 1871-2001 (Figures 7e-7h). As for the 1957-2001 period, these correlations were obtained by taking the average sunspot value for January-February, and without removing first any additional forcing, in order to illustrate the robustness of the results. Figures $7 \mathrm{e}-7 \mathrm{~h}$ show correlation coefficients that are slightly lower than in the case of the 1957-2001 period, but the same large scale features appear, with in particular the positive correlations over Central Asia in June and over the western Indian Ocean from June until August.

[26] In addition, boundary forcing such as a modification of the Sea Surface Temperature (SST) [Shukla, 1987] that affects the geographical distribution of heat and moisture sources and sinks in the troposphere can also modulate the monsoon and therefore the link between the solar activity and the SST has also been investigated. The role of the SST in the Indian Ocean and more specifically its southern part on the variability of the monsoon have been underlined by a number of studies [Behera and Yamagata, 2001; Terray et al., 2003]. Accordingly, correlation and regression patterns between winter F10.7 and SST have been determined for the period 1957-2001 (no additional forcing considered) and are displayed in Figure 8a. Because of the observed warming of the SST over the Indian Ocean [e.g., Nitta and Yamada, 1989; Terray, 1994; Clark et al., 2000] during this period, SST have been first detrended. Correlation coefficients determination was directly performed on these detrended SST, without attempting at removing other forcings (ENSO, QBO, volcanic). Figure 8a shows a significant cooling of the surface over the southern Indian Ocean and the western Pacific during the pre-monsoon (FebruaryMarch) period associated with higher solar activity. These negative SST anomalies before the monsoon in the southern subtropical Indian Ocean, especially in its eastern part, have been shown to be associated with a weaker ISM, especially in August-September, as described by Terray et al. [2003]. The investigation of the reasons why colder temperatures are present to the west of Australia before the monsoon are beyond the scope of this paper and remain to be investigated. We have however observed that both the OLR (Outgoing Longwave Radiation, available after 1979) and Total Cloud Cover provided by reanalyses (not shown) 
provided hints of an increased cloudiness for high solar activity over this area in northern spring. Negative correlations also appear over about the same area when considering a much longer period (Figure $8 \mathrm{~b}$, valid for the period 1871-2001), but of smaller amplitude and not significant at the $90 \%$ level. Figure 8c, displaying the correlation between February-March SST and IMR over the same period, indicates clearly the relationship between high precipitation and warm temperatures in the southern Indian Ocean. Therefore the colder temperatures over the southern Indian Ocean in case of higher solar activity will correspond to negative rainfall anomalies.

\section{Concluding Remarks}

[27] In this observational study, the associations between the characteristics of the ISM and the 11-year solar cycle have been investigated using a statistical analysis. A wide set of reanalyses has been considered, with special attention paid to the quality of the data, which led us to consider only the period after 1979 for those which assimilated satellite data. A rather complex association between the solar cycle and the monsoon precipitation, with considerable spatial variation, has been observed. The most striking features appear in August and to some extent in July, where in case of higher solar activity, precipitation is reduced over the equatorial Indian Ocean and increased over the western Pacific Ocean, and to a lesser extent over part of the Indian subcontinent. In June, precipitation is reduced over the Arabian Sea. Concerning more specifically the Indian subcontinent, while larger precipitation is generally found along the west coast and south of about $20^{\circ} \mathrm{N}$ for higher solar activity, to the north, rainfall is rather reduced. This could suggest an association between the number and/or the intensity of traveling monsoon depressions coming from the Bay of Bengal and the solar cycle, but more work related to intraseasonal aspects is needed to confirm this point. In terms of circulation, in June, there is strong low level convergence over southern India. In July and August, the monsoon circulation is enhanced, with an increase of the cross equatorial flow. The circulation is also increased over the Bengal Gulf. In terms of vertical velocity, in agreement with CMAP results, maximum solar conditions are associated with anomalous subsidence over the Equatorial Ocean, while increased ascent can be seen to the north, over the Indian Peninsula and southeastern Asia, and over the western Pacific. In September, reduced ascent together with weaker circulation are observed along the axis of the monsoon trough in the Gangetic plains, which reflects a decrease of the rainfall activity; in the south Indian Ocean, the vertical velocity anomalies are in favor of an eastward displacement of the Mascarene High, consistent with a weakening of the monsoon. At $200 \mathrm{hPa}$, from July to September, the Tibetan High is slightly weaker and shifted eastward. It must be noted that a consistent response among NCEP and ERA-40 reanalyses has been obtained. There is a rather fair agreement in terms of wind speeds, with some differences in terms of vertical velocity. Over the areas where there is some disagreement, NCEP results are more in line with CMAP results than ERA-40 results, which tends to partially substantiate results by Gleisner et al. [2005], and Crooks and Gray [2005], although this is probably biased to a certain extent by the fact that CMAP products are not totally independent from NCEP-NCAR products [Xie and Arkin, 1997].

[28] Further investigation has shown that these findings were the result of several mechanisms. On one side, due to the warming of the lower stratosphere, which peaks in July-August, there is some potential for a reduction of the convective activity in the equatorial region and an enhancement of convective activity in off-equatorial regions, which is synonymous of a strengthening of the monsoon. However, this is not the only way by which the 11-year solar cycle and the IMR are related. As a matter of fact an association has been observed between the solar cycle and the mean sea level pressure (mslp) through the march of the monsoon. Higher solar activity leads in particular to a southerly shift of the monsoon trough in June. The Mascarene High remains in a more northwest position leading to an enhanced cross-equatorial flow and a stronger Somali Jet in the western Indian Ocean in July, which blossoms into strong monsoon southwesterly flow in August. Observations covering more than one century (1871-2001) confirm these associations between the solar activity and the surface pressure systems. Besides, the 11year solar cycle is also associated with SST anomalies over the southern Indian Ocean. During solar maximum conditions, the cold SST anomalies of February-March act as weakening the following summer monsoon system as discussed by Terray et al. [2003]. These last associations were determined using longer records (1957-2001) covering 4 solar cycles, and were reproduced but with a much smaller amplitude over the period going from 1871 to present.

[29] This analysis suggests that, as a result of these different processes, the solar cycle is only weakly associated to the ISM as a whole and thus has poor skill in terms of monsoon rainfall forecasting. It is nevertheless clearly associated with tropical and subtropical circulation with a response which has been found to occur on the timescale of months. It must be noted that due to the method adopted here, other indirect ways by which the solar activity could affect the monsoon, such as the modulation of the ENSO/ Indian Ocean Dipole connection [Kodera et al., 2007], have not been explored. More generally, relationships between interdecadal and interannual variability have not been investigated in this paper while they may be significant [Krishnamurthy and Goswami, 2000]. Because of the complexity of these relationships, it is of course essential for the future to conduct, in addition to this type of observational study, modeling studies focusing on the interplay between the essential components of the monsoons to document and explain more firmly the complex interactions between the solar cycle and the ISM.

[30] Acknowledgments. This work was partly supported by the French ANR STT-CLIM. The authors are grateful to G. Meehl for useful comments on the paper. The NCEP-R2 reanalyses and CMAP data sets were provided by the NOAA Climate Center (http://www.cdc.noaa.gov) through ClimServ. ERA-40 data have been obtained from the ECMWF Data Server. Sebastien Masson provided graphical software (SAXO) for plotting the results.

\section{References}

Allan, R. J., and T. J. Ansell (2006), A new globally complete monthly historical gridded mean sea level pressure dataset (HadSLP2): $1850-$ 2004, J. Clim., 19, 5816-5842. 
Annamalai, H., J. M. Slingo, K. R. Sperber, and K. Hodges (1999), The mean evolution and variability of the Asian summer monsoon: Comparison of ECMWF and NCEP/NCAR reanalysis, Mon. Weather Rev., 127, $1157-1186$

Balachandran, N. K., D. Rind, P. Lonergan, and D. T. Shindell (1999), Effects of solar cycle variability on the lower stratosphere and the troposphere, J. Geophys. Res., 104(D22), 27,321-27,339.

Baldwin, M. P., and T. J. Dunkerton (2005), The solar cycle and stratosphere-troposphere dynamical coupling, J. Atmos. Sol. Terr. Phys., 67, $71-82$.

Baldwin, M. P., et al. (2001), The quasi-biennial oscillation, Rev. Geophys., 39, 2, 179-229.

Behera, S. K., and T. Yamagata (2001), Sustropical SST dipole events in the southern Indian Ocean, Geophys. Res. Lett., 28, 327-330.

Bhattacharyya, S., and R. Narasimha (2005), Possible association between Indian monsoon rainfall and solar activity, Geophys. Res. Lett., 32, L05813, doi:10.1029/2004GL021044.

Cadet, D. (1983), The monsoon over the Indian Ocean during summer 1975. Part II: Break and active monsoons, Mon. Weather Rev., 111, 95- 108 .

Clark, C. O., J. E. Cole, and P. J. Webster (2000), Indian Ocean SST and Indian summer rainfall: Predictive relationships and their decadal variability, J. Clim., 13, 2503-2519.

Claud, C., and P. Terray (2007), Revisiting the possible links between the Quasi-Biennial Oscillation and the Indian Summer Monsoon using NCEP R-2 and CMAP fields, J. Clim., 20, 773-787.

Crooks, S. A., and L. J. Gray (2005), Characterization of the 11-year solar signal using a multiple regression analysis of the ERA-40 Dataset, J. Clim., 18, 996-1015.

Davison, A. C., and D. V. Hinkley (1997), Bootstrap Methods and Their Application, 582 pp., Cambridge Univ. Press, New York.

Donnelly, R. F., H. E. Hinteregger, and D. F. Heath (1986), Temporal variations of solar EUV, UV and 10830- $\mathrm{A}$ radiations, J. Geophys. Res., 91(A5), 5567-5578.

Gleisner, H., and P. Thejll (2003), Patterns of tropospheric response to solar variability, Geophys. Res. Lett., 30(13), 1711, doi:10.1029/ 2003 GL017129.

Gleisner, H., P. Thejll, M. Stendel, E. Kaas, and B. Machenhauer (2005), Solar signals in tropospheric reanalysis data: Comparing NCEP/NCAR and ERA-40, J. Atmos. Sol. Terr. Phys., 67, 785-791, doi:10.1016/ j.jastp.2005.02.001.

Haigh, J. D. (1994), The role of stratospheric ozone in modulating the solar radiative forcing of climate, Nature, 370, 544-546.

Haigh, J. D. (1996), On the impact of solar variability on climate, Science, $272,981-984$.

Haigh, J. D. (2003), The effects of solar variability on the Earth's climate, Philos. Trans. R. Soc. Ser. A and Ser. B, 361, 95-111.

Haigh, J. D., M. Blackburn, and R. Day (2005), The response of tropospheric circulation to perturbations in lower-stratospheric temperature, J. Clim., 18, 3672-3685.

Hines, C. O. (1974), A possible mechanism for production of Sun-weather correlations, J. Atmos. Sci., 31, 589-591.

Hood, L. L., J. Jirikowic, and J. P. McCormack (1993), Quasi-decadal variability of the stratosphere: Influence of long-term solar ultraviolet variations, J. Atmos. Sci., 50, 3941-3958.

Jagannathan, P., and H. N. Bhalme (1973), Changes in the pattern of distribution of southwest monsoon rainfall over India associated with sunspots, Mon. Weather Rev., 101, 691-700.

Kalnay, E., et al. (1996), The NCEP/NAR 40-year reanalysis project, Bull. Am. Meteorol. Soc., 77, 437-471.

Kanamitsu, M., W. Ebisuzaki, J. Woolen, S. K. Yand, J. J. Hnilo, M. Fiorino, and G. L. Potter (2002), NCEP-DOE AMIP-II reanalysis (R-2), Bull. Am. Meteorol. Soc., 83, 1631-1643.

Keckhut, P., A. Hauchecorne, and M. L. Chanin (1995), Midlatitude longterm variability of the mid- atmosphere: Trends and cyclic and episodic changes, J. Geophys. Res., 100(D9), 18,887-18,897.

Keckhut, P., C. Cagnazzo, M. L. Chanin, C. Claud, and A. Hauchecorne (2005), The effect of the 11-year solar-cycle on the temperature in the upper-stratosphere and mesosphere: Part I Assessment of the observations, J. Atmos. Sol. Terr. Phys., 67, 940-947, doi:10.1016/ j.jastp.2005.01.008.

Kodera, K. (1991), The solar and equatorial QBO influences on the stratospheric circulation during the early northern hemisphere winter, Geophys. Res. Lett., 18(6), 1023-1026.

Kodera, K. (2004), Solar influence on the Indian Ocean monsoon through dynamical processes, Geophys. Res. Lett., 31, L24209, doi:10.1029/ 2004GL020928.
Kodera, K., and K. Shibata (2006), Solar influence on the tropical stratosphere and troposphere in the northern summer, Geophys. Res. Lett., 33, L19704, doi:10.1029/2006GL026659.

Kodera, K., K. Coughling, and O. Arakawa (2007), Possible modulation of the connection between the Pacific and Indian Ocean variability by the solar cycle, Geophys. Res. Lett., 34, L03710, doi:10.1029/ 2006GL027827.

Krishnamurthy, V., and B. N. Goswami (2000), Indian monsoon-ENSO relationship on interdecadal timescale, J. Clim., 13, 579-595.

Labitzke, K., and H. van Loon (1997), The signal of the 11-year sunspot cycle in the upper troposphere-lower stratosphere, Space Sci. Rev., 80, $393-410$

Lau, K. M., and M. J. Nath (2000), Impact of ENSO on the variability of the Asian-Australian monsoons as simulated in GCM experiments, J. Clim., 13, 4287-4309.

Lean, J. L. (1989), Contribution of ultraviolet irradiance variations to changes in the sun's total irradiance, Science, 244, 187-200.

Meehl, G. A., W. M. Washington, T. M. L. Wigley, J. M. Arblaster, and A. Dai (2003), Solar and Greenhouse gas forcing and climate response in the 20th century, J. Clim., 16, 426-444.

Meehl, G. A., J. M. Arblaster, G. Branstator, and H. van Loon (2008), A coupled air-sea response mechanism to solar forcing in the Pacific region, J. Clim., in press.

Mehta, V. M., and K. M. Lau (1997), Influence of solar irradiance on the Indian monsoon-ENSO relationship at decadal-multidecadal time scales, Geophys. Res. Lett., 24(2), 159-162.

Nitta, T., and S. Yamada (1989), Recent warming of tropical sea surface temperature and its relationship to the Northern Hemisphere, J. Meteorol. Soc. Jpn., 67, 375-383.

Parthasarathy, B., A. A. Munot, and D. R. Kothawale (1995), All India monthly and seasonal rainfall series: 1871-1993, Theor. Appl. Climatol., 49, $217-224$

Salby, M. L., and P. F. Callaghan (2006), Evidence of the solar cycle in the tropical troposphere, J. Geophys. Res., 111, D21113, doi:10.1029/ 2006JD007133.

Shindell, D., D. Rind, N. Balachandran, J. Lean, and P. Lonergan (1999), Solar cycle variability, ozone, and climate, Science, 284, 305-308.

Shukla, J. (1987), Long-range forecasting of monsoons, in Monsoons, edited by J. S. Fein and P. L. Stephens, pp. 523-548, John Wiley, New York.

Simmons, A. J., and J. K. Gibson (2000), The ERA-40 project plan, ERA40 Project Rep. Ser., 2000, 1, 63 pp., ECMWF, Reading, UK.

Smith, T. S., and R. W. Reynolds (2003), Extended reconstruction of global sea surface temperatures based on COADS data (1854-1997), J. Clim. 16, $1495-1510$

Smith, T. S., and R. W. Reynolds (2004), Improved extended reconstruction of SST (1854-1997), J. Clim., 17, 2466-2477.

Terray, P. (1994), An evaluation of climatological data in the Indian ocean area, J. Meteorol. Soc. Jpn., 72, 359-386.

Terray, P. (1995), Space/time structure of monsoons interannual variability, J. Clim., 8, 2595-2619.

Terray, P., P. Delecluse, S. Labattu, and L. Terray (2003), Sea surface temperature associations with the late summer monsoon, Clim. Dyn., $21,593-618$.

van Loon, H., G. A. Meehl, and J. M. Arblaster (2004), A decadal solar effect in the tropics in July-August, J. Atmos. Sol. Terr. Phys., doi:10.1016/j.jastp.2004.06.003.

van Loon, H., G. A. Meehl, and D. J. Shea (2007), Coupled air-sea response to solar forcing in the Pacific region during northern winter, J. Geophys. Res., 112, D02108, doi:10.1029/2006JD007378

Xie, P., and P. A. Arkin (1996), Analyses of global monthly precipitation using gauge observations, satellite estimates, and numerical model predictions, J. Clim., 9, 840-858.

Xie, P., and P. A. Arkin (1997), Global precipitation: A 17-year monthly analysis based on gauge observations, satellite estimates and numerical model outputs, Bull. Am. Meteorol. Soc., 78, 2539-2558.

C. Claud and B. Duchiron, Laboratoire de Meteorologie Dynamique/Institut Pierre-Simon Laplace/Centre National de la Recherche Scientifique, Ecole Polytechnique, 91128 Palaiseau, France. (claud@1md.polytechnique.fr)

P. Terray, Laboratoire d'Oceanographie et du Climat: Experimentations et Approaches Numeriques/Istitut Pierre-Simon Laplace/Centre National de la Recherche Scientifique, 75252 Paris, France. 